\title{
Seroprevalence of Toxoplasma gondii among pregnant women attending antenatal clinics at Hawassa University comprehensive specialized and Yirgalem General Hospitals, in Southern Ethiopia
}

\author{
Demissie Assegu Fenta
}

\begin{abstract}
Background: Toxoplasmosis is caused by infection with the protozoan parasite Toxoplasma gondii. It is acquired by consumption of raw or undercooked meat containing tissue cyst, food or water contaminated with oocyst and congenital infection through the placenta leading to serious congenital abnormalities in the fetus like miscarriage, stillbirth, intrauterine death and neurologic defects. Therefore; this study was aimed to determine the prevalence of toxoplasmosis infection and its possible risk factors associated with pregnant women attending antenatal clinics in Hawassa and Yiregalem Hospitals, Southern Ethiopia.

Methods: A hospital-based cross-sectional study was conducted from December 2016 to May 2017. The study was done in antenatal care clinics of Hawassa and Yiregalem Hospitals in Southern, Ethiopia. Five hundred pregnant women were interviewed with a pretested structured questionnaire to collect risk factors and socio-demographic data. Blood samples were collected and serum was separated and tested for anti- Toxoplasma gondii antibodies using ELISA (Enzyme-linked Immunosorbent Assay). Data were analyzed using SPSS version 20 statistical software. The risk factors were tested for significance using Bivariate and multivariate analysis. $P$-value $<0.05$ was considered statistically significant.

Results: The weighted prevalence of this study was $81.8 \%$ for the anti- Toxoplasma gondii antibody. Almost all participants (99.6\%) had no information about the disease. A significant association was observed between seroprevalence and contact with domestic cats $(\mathrm{OR}=1.206,95 \% \mathrm{Cl}(1.627-2.206, P=0.043)$, consumption of raw meat $(\mathrm{OR}=0.848,95 \% \mathrm{Cl}: 1.517-2.941, P=0.019)$ and unpasteurized milk $(\mathrm{OR}=0.871,95 \% \mathrm{Cl} 1.531-2.221, P=0.032)$. A significant association was not observed between seroprevalence and age, history of abortion, and blood transfusion.

Conclusions: The findings of this study demonstrated a relatively higher prevalence of seropositivity than studies reported from other countries. Existence of domestic cats at home, consumption of undercooked meat and unpasteurized milk were identified as risk factors for T. gondii infection. Therefore, a health education program to increase the mother's knowledge about toxoplasmosis towards avoiding eating undercooked meat, contact with cats and consumption of unpasteurized milk during pregnancy is recommended. Furthermore, our results suggested that the implementation of newborn screening and follow-up testing can lead to reducing of toxoplasmosis associated complications.
\end{abstract}

Keywords: T. Gondii, Pregnant women, Hawassa, Yirgalem, Ethiopia

(c) The Author(s). 2019 Open Access This article is distributed under the terms of the Creative Commons Attribution 4.0 International License (http://creativecommons.org/licenses/by/4.0/), which permits unrestricted use, distribution, and reproduction in any medium, provided you give appropriate credit to the original author(s) and the source, provide a link to the Creative Commons license, and indicate if changes were made. The Creative Commons Public Domain Dedication waiver (http://creativecommons.org/publicdomain/zero/1.0/) applies to the data made available in this article, unless otherwise stated. 


\section{Background}

Toxoplasma gondii ( $T$. gondii) is an obligate singlecelled, intracellular protozoan parasite belonging to phylum Apicomplexa that causes a zoonotic infectious disease, toxoplasmosis which can infect wide-ranging warm-blooded vertebrates such as human as well as other warm-blooded domestic and wild animals [1-3]. This parasitic infection is a neglected disease out of five parasitic infections which have been classified as a concern to public health by Center for disease control (CDC) or a member of TORCH group infectious agents; consisting of Rubella, Cytomegalovirus, Herpes viruses and Treponema pallidum, which causes infection of the fetus transplacentally with congenital abnormalities, and even fetal loss both in humans and animals [4].

The infection has a worldwide prevalence of about one-third of the population all over the world to be exposed to this parasite. However; the incidence rate of 400-4000 congenital toxoplasmosis cases per year has been reported [5] Its prevalence have been reported from various parts of the world such as United State $15 \%$ from childbearing age women, France (44\%) and Indonesia greater than $60 \%$ from pregnant women, 3075\% in Latin America, parts of Eastern/Central Europe, the Middle East, parts of south-east Asia and Africa from pregnant women [6].

The prevalence has been declining in parts of Eastern and central Europe over the past three to four decades [7] High prevalence of the infection have been reported from pregnant women and women of childbearing age in Latin America, the Middle East, parts of south-east Asia [6] In Africa, particularly in Sub-Saharan Africa the prevalence of $T$. gondii is increased in association with HIV [8] . Different prevalence values were reported from different African countries such as Ghana 92.5\% [9], and Sudan 79.8\% [10]. Most pregnant women infected with T. gondii are chronically infected while few acquire the infection. However; pregnant women with acute infection during pregnancy are at risk of congenitally transmitting the infection to the fetus [11].

In Ethiopia, the seroprevalence T.gondii range from $20.2 \%$ from the general population to $90 \%$ among HIV patients [8] According to the Ethiopian Demographic and Health Survey (EDHS 2016) the infant mortality rate was 48 deaths per 1000 live birth among these deaths 28 of them were due to infection [12] Furthermore; studies from large hospitals in the country also reported higher prevalence rates of T.gondii $83.6 \%$ from Jimma [13] 88.6\% Gondar [14], 85.4\% Addis Abeba [15], 81.4\% Central Ethiopia [16], 79.3\% Arba Minch hospital [17] and 85.3\% from Bench Maji zone [18].

This parasite has a wide host range, infecting most warm-blooded species but the life cycle is completed only in felis [4] humans usually become infected by ingesting of raw or undercooked meat containing tissue cysts, drinking of unpasteurized milk, ingestion of vegetables contaminated with soil, water and food with sporulated oocysts shed-cat faece [9].

This parasite is primarily very significant in pregnancy as it can cross the placental barrier to infect the fetal tissues and thereby cause congenital deformities such as hydrocephaly, mental retardation or chorioretinitis [19-21]. There are rare occasions of transmission through tachyzoites contained in blood products during (blood transfusion, organ or tissue transplantation), consumption of vegetables and needle-stick injuries or cuts [4]. Risk group individuals like laboratory workers who handle infected blood can also acquire infection through accidental inoculation [4]. In Immunocompetent individuals, T. gondii causes a latent infection characterized by the persistence of the organism primarily in the brain, skeletal muscle, and heart tissues without causing clinical symptoms. However, in chronically infected individuals with impaired cell-mediated immunity symptomatic disease more likely occurs as a result of the recurrence of latent infection $[22,23]$.

Individuals with a weakened immune system, such as those infected with HIV and Pregnant women may become seriously ill, and infection can occasionally be fatal and also results in hospitalization $[4,12]$ If the diagnosis is delayed, it might have a great contribution as it has the ability to cause, spontaneous abortion, stillbirth and preterm deliveries [15] and unavoidable and irreversible fetal damage might also take place [24, 25].

In spite of the widespread practice of keeping cats as domestic animals and the presence of stray cats, the habit of eating raw meat, consumption of unpasteurized milk and suitable climatic conditions favors the survival of the parasite in the study area [26, 27]. To the best of our knowledge, there is no regular serological screening of pregnant women for $T$. gondii infection. Moreover, there is no documented data about the prevalence of the disease and associated risk factors in the study area. It is believed that antenatal data on this parasitic disease in the study area would give baseline information about the prevalence of $T$. gondii in pregnant women and also for the planning and implementation of $T$. gondii comprehensive diagnostic, control and prevention strategies. Therefore, this study was aimed to determine the seroprevalence of $T$. gondii infection and its risk factors among pregnant women attending ANC clinics' on the emphasis of screening and management of pregnant women in Hawassa University and Yirgalem hospitals, Southern Ethiopia.

\section{Methods}

\section{Study design, area and period}

The cross-sectional hospital-based study was conducted from December 2016-March 2017 among pregnant women to assess the seroprevalence of $T$. gondii at 
Yirgalem and Hawassa University comprehensive Specialized Hospitals ANC clinics. These two hospitals are located in Southern Nations and Nationalities People's Region (SNNPR), 345 and $275 \mathrm{kms}$ apart from Addis Abeba the capital city of Ethiopia respectively. While Yirgalem hospital is $70 \mathrm{kms}$ from the regional capital city Hawassa. These two larger hospitals of the region are serving as teaching, training and clinical service centers. The ANC clinic of Yirgalem Hospital serves more than 25 pregnant women per day with 69 beds for both prenatal and postnatal services. However, 45 pregnant women were visiting Hawassa University Hospital ANC clinic per day and about 200 beds are giving service for both prenatal and postnatal services.

\section{Study population}

A total of 500 pregnant women attending ANC clinics of Yirgalem and Hawassa University comprehensive Specialized Hospitals were our study population. Pregnant women who had emergency conditions and requiring urgent intervention and who refused to give consent were not included in the study.

\section{Sample size and sampling technique}

Sample size was determined using single population proportion formula as 500 based on a prevalence of $43.9 \%$ taken from a study conducted in Bench Maji zone, Ethiopia [17], with 95\% confidence interval and a maximum discrepancy of $10 \%$ between the sample and the underline population for Yirgalem hospital gives 193 pregnant women and prevalence $81 \%$ from a study conducted in Jimma to select 307 pregnant women from Hawassa university hospital [13]. Finally, a total of 500 pregnant women were interviewed. Of these 6 of them were no responses.

\section{Data collection}

Socio-demographic characteristics and data on exposure to possible risk factors were collected for each study participant using a structured questionnaire consisting of consumption of raw meat and unwashed raw vegetables, presence of a domestic cat at home, history of abortion, blood transfusions and others.

Venous blood samples $(5 \mathrm{ml})$ were collected for a routine antenatal check-up and for our study after obtaining consent from each study participants by strictly following the standard operating procedure in place. The blood samples were clotted for $30 \mathrm{~min}$ at room temperature and centrifuged at $3000 \mathrm{rpm}$ for $5 \mathrm{~min}$ to separate serum which was kept at $-20^{\circ} \mathrm{C}$ in the refrigerator until it was transported to the laboratory and serological tests were carried out. The questionnaire was pretested at Adare General Hospital before data collection and administered orally before blood sample collection and checked for its consistency.
The serum was tested for anti-T. gondii IgM and IgG antibodies using Enzyme-Linked Immunosorbent Assay following the method of Engvall and his colleagues with the commercial ENZYWELL TOXOPLASMA IgG and IgM KIT, using (Siemens Healthcare Diagnostics Products GmbH, Marburg, Germany). According to the manufacturer's instructions (Engvall and Perlmann, 1971, 1972). The different values of the calibrator identified the upper limit of the reference range of non-infected individuals (Cut-off). In addition to that, the findings were evaluated quantitatively by calculating a ratio of the extinction value of the control or patient samples over the extinction value of the calibrator. If the absorbance of the sample is higher than that of the Cut-off (> 1.3 for IgG and $>1.2$ for IgM), the sample was considered positive for the presence of specific antibodies and negative if it was $<0.7$ of IgG and $<0.8$ for IgM. In case borderline test results of both $(0.7-1.3$ for IgG and $0.8-$ 1.2 for IgM), tests were repeated.

\section{Statistical analysis}

All collected data from the questionnaire and laboratory were checked for completeness and consistency, entered into a computer, cleaned and analyzed using SPSS version 20 software package. Descriptive statistics were used to calculate the demographic data of the study participants. Bivariate and multivariate logistic regressions were used to assess the association between potential risk factors considered and $T$. gondii infection. Variables with $P$-value $<0.25$ by the bivariate analysis were entered into the multivariate model. A multivariate logistic regression, $p$-value $<0.05$ was considered as statistically significant for all variables.

\section{Ethical consideration}

The study was ethically cleared by the Institutional Review Board (IRB) of Hawassa University College of medicine and health science on 14 February 2017 and approved the proposal with (Reference number: IRB -057-14- 02/2017). An original copy of the approval, as well as the consent form, is available upon request.. Permission letter was obtained from SNNPR Sidama Zone Health Bureau, Yirgalem and Hawassa University hospital administrations.

The purpose and importance of the study were explained to each study participant and parents and guardians of a few minorities. Finally, consent instead of assent was secured from all participants including minor participants. Permission was obtained from parents or guardians to obtained consent from minor participants who have ethical dilemmas based on the Ethiopian national research Ethics review guideline. Furthermore, the minor participant should be given appropriate information based on the participant's level of 
comprehension and where early marriage is common like our study area. Therefore; consent was taken from each participant who was under the age of 18 years with a participant affirmative agreement to participate in the research according to the guideline and for the purpose of data quality. To ensure confidentiality of participant's information, anonymous typing was applied.

\section{Result}

\section{Socio-demographic characteristics}

A total of 494 pregnant women age between 15 to 42 years with a mean age of $4.6 \pm 26.47$ years attending ANC clinics of Yirgalem and Hawassa University hospital were selected and participated in the study. The majority $(60.8 \%)$ of the study participants were found within the age group of 25-34.9 years. Almost all, (99.6\%) of the participants had no information about the disease toxoplasmosis and its mode of transmission. Of all participants, 333 (67.5\%) and 161(32.5\%) were urban and rural residents respectively. According to their gestational age 101(20.4\%), 180(36.4\%) and 213(43.2\%) were at first' second and third trimester respectively. $168(53.9 \%)$ of participants had at least elementary education. 446(90.3\%) were married and 246(49.7\%) were housewives. The seroprevalence of $T$. gondii and other demographic characteristics of the pregnant women is indicated in (Table 1).

\section{Seroprevalence of $T$. gondii and associated factors}

Among 494 participants tested for anti-T. gondii IgG and IgM antibodies, 404 were found to be seropositive, giving an overall prevalence of $81.8 \%$. Among the total seropositive 370 (74.9\%), 19(3.8\%) and 15(3.1\%) were positive for Toxoplasma IgG, IgM, and both IgG and IgM respectively. The proportion of IgG-/ IgM-, IgG $+/ \operatorname{IgM}+, \operatorname{IgG}-/$ IgM+ and IgG +/ IgM- in this study was $124 / 475,370 / 19,124 / 19$ and 370/475 respectively. The combination of both immunoglobulins was stratified as IgG and IgM assay expressed as both negative (never infected), IgM only (acute infection), IgM and IgG positive (recent infection) and IgG only (latent infection). The presence of specific IgM is generally suggested to be associated with acute infection. However, this may not be the case in toxoplasmosis, as the continuation of IgM for several months in the sera may interfere in calculating the time of exposure.

Of the total 494 pregnant women, 301(60.8\%) were within the age range of 25-34.9 years. Among these 250(61.9\%) were positive for anti- T. gondii antibody. The prevalence of $T$. gondii increases with age but not significantly associated with $T$. gondii seropositivity ( $p=$ $0.86)$. In the current study $59(11.9 \%)$ were illiterate among these 51(12.6\%) were positive for the T. gondii antibody. But there was no significant difference between seropositivity and being illiterate and literate $(P=0.595)$. In this study, a significant difference was not indicated between seropositivity and participants with different occupations $(P=0.542)$. From all participants responded $23(4.7 \%)$ have a history of blood transfusion. Of these $18(78.3 \%)$ were seropositive for $T$. gondii (Table 1).

Based on their gestational period the distribution of participants was 101(20.4\%), 180(36.4\%) and 213(43.2\%) in the first, second and third trimester respectively. Among these 79(19.6\%) 140(34.7\%) 185(45.8\%) were seropositive for $T$. gondii. Indicated that as the gestational period increases the positivity of $T$. gondii.antibody also showed an increasing trend in this study.

Pregnant women who had close contact with domestic cats were $130(26.3 \%)$. Of whom 104(80\%) were seropositive for T. gondii. Antibody and a significant association between contact with domestic cats at home and T. gondii antibody seropositivity were indicated, $(\mathrm{OR}=1.206$, 95\% CI: $1.625-2.206, P=0.043)$.

In the current study from 291(58.9\%) participants who have the habit of eating raw meat $242(83.2 \%)$ were positive for $T$. gondii antibodies and there was a significant association between eating raw meat and T. gondii. Seropositivity $(\mathrm{OR}=0.848,95 \% \mathrm{CI} 1.517-1.941, P=0.019)$. Among a total of pregnant women who participated in this study $187(37.8 \%)$ have a habit of drinking unpasteurized milk and 153(81.8\%) of them were positive for $T$. gondii. Seropositivity and showed a significant association between seropositivity of $T$. gondii and using unpasteurized milk (OR $=0.871,95 \% \mathrm{CI}, 1.531-2.221$, $P=0.033)$. Other risk factors and their significant associations were indicated in the table below (Table 2).

In the current study, the seropositivity of IgM antibody for pregnant women who have contact with domestic cats and those who have a habit of eating raw meat were significantly associated at $(\mathrm{OR}=0.628,95 \% \mathrm{CI}, 1.216$ $\left.1.560, P=0.001^{*}\right)$ and $(\mathrm{OR}=0.45,95 \% \mathrm{CI}, 1.272-1.504$, $P=0.001)$ respectively.

\section{Discussion}

This study is one of the few studies carried out in the southern region of Ethiopia to explore the seroprevalence of $T$. gondii infection among pregnant women at Hawassa and Yirgalem hospital.

Toxoplasmosis is a curable but potentially fatal disease and its long term complications following congenital infection and its capacity to cause life-threatening opportunistic infections in immunosuppressed conditions is a major problem in most communities with a high prevalence of $T$. gondii infection [28].

In the present study, there was a non-statistically significant increase in the seropositivity of anti- $T$. gondii antibody in the age group of $25-34.9$ (60.8\%) (Table 1) 
Table 1 Distribution of T. gondii infection along with demographic characteristics of the pregnant women $(n=494)$, Hawassa Ethiopia, 2017

\begin{tabular}{|c|c|c|c|c|c|c|c|}
\hline \multirow{2}{*}{$\begin{array}{l}\text { Demographic } \\
\text { Characteristics }\end{array}$} & \multirow[t]{2}{*}{ Total n (\%) } & \multicolumn{2}{|l|}{ Seroprevalence } & \multirow[t]{2}{*}{$P$-Value } & \multirow[t]{2}{*}{ COR 95\% (Cl) } & \multirow[t]{2}{*}{$P$-Value } & \multirow[t]{2}{*}{ AOR 95\% (Cl) } \\
\hline & & Negative n (\%) & Positive $\mathrm{n}(\%)$ & & & & \\
\hline \multicolumn{8}{|l|}{ Age group (in Years) } \\
\hline $15-24.9$ & $161(\%)$ & $34(37.8 \%)$ & $127(31.6 \%)$ & 0.501 & $0.49(0.486-1.505)$ & 0.482 & $0.69(0.248-1.951)$ \\
\hline $25-34.9$ & $301(60.8 \%)$ & $51(56.7 \%)$ & $250(61.9 \%)$ & & $0.51(0.499-1.519)$ & 0.860 & $0.85(0.334-2.459)$ \\
\hline$>35^{\mathrm{a}}$ & $32(6.5 \%)$ & $5(5.6 \%)$ & $27(6.7 \%)$ & & $0.53(0.524-1.543)$ & & \\
\hline \multicolumn{8}{|l|}{ Residence } \\
\hline Urban & $333(67.5)$ & $57(63.3 \%)$ & $276(68.3 \%)$ & 0.001 & $0.93(1.21-2.30)$ & 0.001 & $1.25(1.043-2.012)$ \\
\hline Rural $^{a}$ & $161(32.5 \%)$ & $33(36.7 \%)$ & $128(31.7 \%)$ & & $1.16(0.851-1.573)$ & & \\
\hline \multicolumn{8}{|l|}{ Education status } \\
\hline Illiterate & $59(11.9 \%)$ & $8(8.9 \%)$ & $51(12.6 \%)$ & 0.595 & $0.69(0.589-1.608)$ & 0.697 & $1.20(0.480-3.002)$ \\
\hline Elementary & 168(53.9\%) & $32(35.6 \%)$ & 136(33.7\%) & & $0.59(0.578-2.597)$ & 0.507 & $0.80(0.414-1.545)$ \\
\hline Secondary & $166(33.5)$ & $34(37.8 \%)$ & $132(32.7 \%)$ & & $0.63(0.619-1.638)$ & 0.347 & $0.73(0.380-1.405)$ \\
\hline College and above ${ }^{a}$ & $101(20.4)$ & $16(17.8 \%)$ & $85(21 \%)$ & & $0.85(0.846-2.860)$ & & \\
\hline \multicolumn{8}{|l|}{ Marital status } \\
\hline Married & $446(90.3 \%)$ & $81(90 \%)$ & 365(90.3\%) & 0.697 & $0.73(0.698-2.716)$ & 0.004 & - \\
\hline Single & $30(6.1 \%)$ & $5(5.6 \%)$ & $25(6.2 \%)$ & & $0.88(0.672-2.690)$ & 1.00 & - \\
\hline Divorced & $15(3 \%)$ & $4(4.4 \%)$ & $11(2.7 \%)$ & & $0.89(0.782-1.798)$ & 1.00 & - \\
\hline Widowed $^{a}$ & $3(0.6 \%)$ & $0(0 \%)$ & $3(0.7 \%)$ & & 1.00 & & \\
\hline \multicolumn{8}{|l|}{ Occupation } \\
\hline Housewife & $246(49.7 \%)$ & $44(48.9 \%)$ & $202(50 \%)$ & 0.542 & $0.64(0.531-1.551)$ & 0.584 & $1.29(0.523-3.160)$ \\
\hline Health worker & 19(3.8\%) & $3(3.3 \%)$ & $16(4 \%)$ & & 1.00 & 0.598 & $1.49(0.336-6.633)$ \\
\hline Employed & $133(26 . .9 \%)$ & 28(31.1\%) & $105(26 \%)$ & & $0.52(0.508-1.528)$ & 0.919 & $1.05(0.412-2.677)$ \\
\hline Daily labor & $12(2.4 \%)$ & $3(3.3 \%)$ & $9(2.2 \%)$ & & 1.00 & 0.826 & $0.84(0.178-3.967)$ \\
\hline Merchant & $52(10.5 \%)$ & $5(5.6 \%)$ & $47(11.6 \%)$ & & $0.58(0.469-2.489)$ & 0.128 & $0.84(0.178-3.967)$ \\
\hline Student ${ }^{a}$ & $32(6.5 \%)$ & $7(7.8 \%)$ & $25(6.2 \%)$ & & $0.86(0.851-1.865)$ & & \\
\hline \multicolumn{8}{|l|}{ Gestational age } \\
\hline 1st trimester & $101(20.4 \%)$ & $22(24.4 \%)$ & $79(19.6 \%)$ & 0.019 & $1.04(1.723-2.273)$ & 0.001 & $1.34(1.272-$ \\
\hline 2nd trimester & $180(36.4)$ & $40(44.4 \%)$ & $140(34.7 \%)$ & & $1.24(1.034-2.041)$ & 0.028 & 1.532)) \\
\hline $3 r d$ trimester $^{a}$ & $213(43.2 \%)$ & $28(31.1 \%)$ & $185(45.8 \%)$ & & $0.41(1.032-1.039)$ & 0.030 & $1.53(1.312-2.900)$ \\
\hline \multicolumn{8}{|l|}{ Place of previous birth } \\
\hline No birth & $150(30.3 \%)$ & $32(35.6 \%)$ & $118(29.2 \%)$ & 0.135 & $0.47(0.459-1.478)$ & 0.315 & $0.77(0.462-1.282)$ \\
\hline Home & $95(19.2 \%)$ & 15(16.7\%) & $80(19.8 \%)$ & 0.200 & $0.48(0.459-1.478)$ & 0.013 & $1.59(1.113-2.115)$ \\
\hline Health institution ${ }^{a}$ & $249(50.5 \%)$ & $43(47.8 \%)$ & $206(51 \%)$ & & $0.49(0.476-1.495)$ & 0.473 & \\
\hline
\end{tabular}

COR Crude Odds Ratio, AOR Adjusted Odds Ratio, Cl Confidence Interval, adjusted variable

study participants. However, the finding was in agreement with other similar studies in which increasing age was more associated with chronic infection [18, 29-31].

In this study $333(67.5 \%)$ and $161(32.5 \%)$ were urban and rural residents respectively. However, there were no significant differences in the seroprevalence of anti- $T$. gondii antibodies with the residence. Similar findings were reported from [32-34]. On the other hand, opposite findings were reported from studies conducted in [33-36] between being rural or urban and T. gondii seropositivity.
The highest T.gondii antibodies were found 213 (43.2\%) in those pregnant women in the third trimester and there was a statistically significant association between the gestational age at (first, second and third trimester) and seropositivity of T.gondii antibody. This result is in agreement with other studies reported from Ethiopia [17] and Saud Arabia [33] but different reports from this finding were reported from Ethiopia [18, 31], Rwanda [30] and Egypt [37]. In this study 168(53.9\%) of the participants had at least elementary education 
Table 2 Toxoplasmosis and associated risk factors among pregnant women attending ANC of Yirgalem and Hawassa hospitals southern Ethiopia

\begin{tabular}{|c|c|c|c|c|c|c|c|}
\hline \multirow[t]{2}{*}{ Risk factors } & \multicolumn{2}{|c|}{ Toxoplasma gondii Ab. } & \multirow[t]{2}{*}{ Total N(\%) } & \multirow[t]{2}{*}{$P$-value } & \multirow[t]{2}{*}{ COR 95\% (Cl) } & \multirow[t]{2}{*}{$P$-value } & \multirow[t]{2}{*}{ AOR 95\% (Cl) } \\
\hline & Positive & Negative & & & & & \\
\hline \multicolumn{8}{|l|}{ Surgery } \\
\hline Yes & 69(83.1\%) & $14(16.8 \%)$ & $83(16.8)$ & 0.727 & $0.89(0.478-1.673)$ & 0.727 & $1.12(0.598-2.091)$ \\
\hline $\mathrm{No}^{\mathrm{a}}$ & $335(81.5 \%)$ & $76(18.5 \%)$ & $411(83.2 \%)$ & & & & \\
\hline \multicolumn{8}{|l|}{ Blood transfusion } \\
\hline Yes & 18(78.3\%) & $5(21.7 \%)$ & $23(4.7 \%)$ & 0.654 & $1.26(0.456-3.492)$ & 0.655 & $1.26(0.456-3.492)$ \\
\hline $\mathrm{No}^{\mathrm{a}}$ & $386(82 \%)$ & $85(18 \%)$ & $471(95.3 \%)$ & & & & \\
\hline \multicolumn{8}{|l|}{ History of abortion } \\
\hline Yes & $52(77.6 \%)$ & $15(22.4 \%)$ & $67(13.6 \%)$ & 0.342 & $1.35(0.724-2.532)$ & 0.343 & $1.35(0.724-2.532)$ \\
\hline $\mathrm{No}^{\mathrm{a}}$ & $352(82.4 \%)$ & $75(17.6 \%)$ & $427(86.4 \%)$ & & & & \\
\hline \multicolumn{8}{|l|}{ Presence of cats } \\
\hline Yes & 104(80\%) & $26(20 \%)$ & $130(26.3 \%)$ & 0.047 & $1.21(1.725-2.006)$ & 0.043 & $1.72(1.625-2.206)$ \\
\hline $\mathrm{No}^{\mathrm{a}}$ & $301(82.7 \%)$ & $63(17.3 \%)$ & $364(73.7 \%)$ & & & & \\
\hline \multicolumn{8}{|c|}{ Keep dogs in house } \\
\hline Yes & $124(84.4)$ & $23(15.6 \%)$ & 147(29.9\%) & 0.365 & $0.79(0.468-1.325)$ & 0.366 & $0.79(0.468-1.323)$ \\
\hline $\mathrm{No}^{\mathrm{a}}$ & 280(80.9\%) & $66(19.1 \%)$ & $346(70 \%)$ & & & & \\
\hline \multicolumn{8}{|c|}{ Raw meat eating habit } \\
\hline Yes & $242(83.2 \%)$ & $49(16.8 \%)$ & $291(58.9 \%)$ & 0.036 & $1.76(1.570-2.209)$ & 0.019 & $1.65(1.517-1.941)$ \\
\hline $\mathrm{No}^{\mathrm{a}}$ & 163(80.3\%) & 40(19.7\%) & $203(41.1)$ & & & & \\
\hline \multicolumn{8}{|l|}{ Types of milk } \\
\hline Unpasteurized & 153(81.8\%) & $34(18.2 \%)$ & 187(37.8\%) & 0.015 & $1.45(1.182-1.688)$ & 0.033 & $1.87(1.531-2.221)$ \\
\hline Pasteurized & 196(84.2\%) & $37(15.8 \%)$ & $233(47.2 \%$ & & & & \\
\hline Not at all ${ }^{a}$ & $55(75.3 \%)$ & $18(24.6 \%)$ & $74(18.8)$ & & & & \\
\hline \multicolumn{8}{|l|}{ Raw vegetables } \\
\hline Yes & $334(82.3 \%)$ & $72(17.7 \%)$ & $406(82.2 \%)$ & 0.619 & $0.60(0.591-1.610)$ & 0.826 & $0.94(0.535-1.648)$ \\
\hline $\mathrm{No}^{\mathrm{a}}$ & $71(80.7 \%)$ & $17(19.3 \%)$ & $88(17.8 \%)$ & & & & \\
\hline \multicolumn{8}{|l|}{ Contact with soil } \\
\hline Yes & $125(79.7 \%)$ & $32(20.3 \%)$ & 157(31.8\%) & 0.475 & $1.19(0.735-1.936)$ & 0.475 & $1.19(0.735-1.936)$ \\
\hline $\mathrm{No}^{\mathrm{a}}$ & $279(82.8 \%)$ & $58(17.2 \%)$ & $337(68.2 \%)$ & & & & \\
\hline \multicolumn{8}{|c|}{ Sources drinking water } \\
\hline \multirow[t]{2}{*}{ Pipe water ${ }^{a}$} & $79(80.6 \%)$ & 19(19.4\%) & $98(19.8 \%)$ & 0.701 & $1.12(0.636-1.962)$ & 0.701 & $1.12(0.636-1.962)$ \\
\hline & $325(82.1 \%)$ & $71(17.9 \%)$ & $396(80.2 \%)$ & & & & \\
\hline \multicolumn{8}{|l|}{ Slaughter house } \\
\hline Yes & $33(89.2 \%)$ & $4(10.8 \%)$ & $37(7.5 \%)$ & 0.509 & $0.48(0.472-1.491)$ & 0.342 & $0.61(0.223-1.681)$ \\
\hline $\mathrm{No}^{\mathrm{a}}$ & $372(81.4 \%)$ & $85(18.6 \%)$ & $457(92.5 \%)$ & & & & \\
\hline
\end{tabular}

COR Crude Odds Ratio, AOR Adjusted Odds Ratio, Cl Confidence Interval, adjusted variable

however, no significant difference was observed between the different levels of education. Similar findings were reported from London [7], Ethiopia and Iran [17, 28], Cameroon [36] and Nigeria [38]. Inconsistent findings to this study were reported from studies from Mexico [29] and Ethiopia [39].

Majority 446(90.3\%) of participants were married. However, marital status was not significantly associated with T.gondii antibody seropositivity. Comparable findings were reported from Ethiopia [18] and Rwanda [30] and the opposite finding was reported from Tobego [40].

The total prevalence of anti-Toxoplasma gondii antibodies in pregnant women in the present was $81.8 \%$. The high prevalence of anti-T. gondii antibodies observed in current study was in agreement with seroprevalence data from previous studies conducted in 
Ethiopia: 90\% from HIV infected and HIV uninfected individuals [22]; 83.6\% among pregnant women in Jimma town [13]; 81.4\% among women of childbearing age [16] and other countries 81.2\% Saudi Arabia [41], 79.8\% Sudan [10] and 74.5\% Democratic Republic of Sao Tome [42]. However, our findings, as well as those of previous works in Ethiopia, were substantially higher than other results which were reported from other countries; $34.1 \%$ in Sudan [43], 30.9\% in Tanzania [34], $40.2 \%$ Nigeria [38], 39.3\% in Tobago [40], This variation might be attributed to climate and cultural differences and hygienic and feeding habit difference of each country.

The prevalence of the current study was higher than other previous studies reported from different countries Tanzania (30.9\%) [34], Nigeria (40.2\%) [38], Tobago (39.3\%) [40], 14 to $25.7 \%$ in Sweden [44], 23.6\% in Italy [45], 0.8\% in Korean [46] and one study $68.4 \%$ in Debre Tabor Ethiopia [47]. On the other hand, higher than the current prevalence were reported from $92.5 \%$ in Accra Ghana [48], 88.6\% in Gondar Ethiopia [14], 86.4\% in Central Ethiopia (86.4\%) [16] and 85.3\% in Mizan Aman general hospital Ethiopia [18].

This difference might be due to the differences in socioeconomic status, personal hygiene practices, feeding habits, deference in testing methods, variation in the immune status of the study participants and sample size of each study.

In our study, a significant association was observed between seroprevalence and ingestion of raw meat $(\mathrm{OR}=$ 0.848, 95\% CI 1.517-1.941, $P=0.019)$ and similar findings were reported from other studies in Ethiopia [18, 39], Egypt [37] and Khartoum Sudan [49]. However, inconsistent findings were reported from Ethiopia and Turkey [16, 32] and Mexico [29, 50]. This difference might be due to the difference in socioeconomic status and feeding habits of study participants. Drinking of unpasteurized milk was significantly associated with seropositivity of $T$. gondii $(\mathrm{OR}=0.871,95 \% \mathrm{CI}, 1.531-$ 2.221, $P=0.033)$. Consistent results were reported from London [7], Khyber [33] and Egypt [37]. Inconsistent results in this study were reported from Ethiopia [16, 32], Cameroon [36] and Burkina Faso [43]. This might be due to the difference in the habit of consumption and handling of milk and milk products in the study participants. Although cats are the definitive hosts that shed oocysts, participants who have close contact with domestic cats found to be significantly associated with $T$. gondii infection with $T$. gondii $(P=0.044)(\mathrm{OR}=1.206$, 95\% CI: 0.725-2.006). Comparable findings were reported from Ethiopia [18], Tobago [40] and Brazil [51]. Different findings to this study were reported from Ethiopia [15, 16], Egypt [37], Mexico [50] and Burkina Faso [52].
Frequently eating unwashed and raw fresh fruits and vegetables showed no significant association with Toxoplasma infection in this study. $(P=0.826)$ (AOR $=0.939$; 95\% CI (0.535-1.648).The finding was in agreement with other studies reported from Ethiopia [15, 39], Korean [46] and Mexico [50]. Incomparable results were reported from Buenous Ires [11] Ethiopia [16] and Egypt [37]. This might be due to the difference in feeding habits and personal hygiene practice of the study participants.

Concerning the experience of blood transfusion, no significant difference was observed $(P=0.655)$ (AOR $=$ $1.261(0.456-3.492)$ among pregnant women who had or did not have a blood transfusion. Furthermore, risk factors like the history of abortion, drinking of unsafe water, contact with dogs working environment like slaughterhouse, surgery, and contact with soil were no significantly associated with $T$. gondii seropositive in this study (Table 2).

\section{Limitations}

We encountered inevitable limitations in the current study in all IgG-/IgM+ participants, follow up serological study was not conducted to prove seroconversion of IgG in these groups of participants. Furthermore; to address the possibility of false-positive IgM results due to the persistence of IgM antibody for several years and Toxoplasma gondii IgM diagnostic test errors were not checked. Future follows up studies among pregnant women as well as, newborns will be important for tracing acute congenital Toxoplasmosis and to avoid false-positive reports due to different reasons.

\section{Conclusion}

The findings of this study demonstrated a relatively higher prevalence of seropositivity than studies reported from other countries. Existence of domestic cats at home, consumption of undercooked meat and unpasteurized milk were identified as risk factors for $T$. gondii infection. Therefore, a health education program to increase the mother's knowledge about toxoplasmosis towards the source of infection, modes of transmission and prevention methods by avoiding eating raw or undercooked meat, contact with cats and consumption of unpasteurized milk during pregnancy is recommended. Advocating for the implementation of control and preventive measures and routine screening services for T. gondii infection to be integrated with other ANC services to identify potential effects of the infection and its management should be considered as the main strategy to minimize congenital toxoplasmosis. Furthermore, our results suggested that the implementation of newborn screening and follow-up testing can lead to reducing of toxoplasmosis associated complications. 


\section{Abbreviations}

ANC: Antenatal care; AOR: Adjusted odds ratio; EDHS: Ethiopian health and demographic survey; ELISA: Enzyme-linked immunosorbent assay; HIV: Human immunodeficiency virus; IgG: Immunoglobulin G; IgM: Immunoglobulin M

\section{Acknowledgments}

The author wishes to thank Hawassa University College of medicine and health science for supporting this research work. I would like to thank the management of Hawassa University and Yirgalem hospitals' gynecology and obstetrics departments for providing the permission to use their facilities and accessing pregnant women The author also wish to thank $S / r$, Bereket Tadesse, S/r Amelwork Ayalew and S/r Eleni Messele for data collection and laboratory technologists Henock Getachew, Abebe kifle and Eshetu Ansebo for their technical support during test procedure. I would like to thank Mr. Kebede Yagne Arbaminch's sub-regional laboratory head for his permission to use his laboratory and ELISA machine and unreserved support and guidance during the performing of the ELISA test and Dr. Dejene Hailu for his support during the analysis of the data. I also wish to thank the study participants without whom the study would not have been possible.

\section{Authors' contributions}

DA conceived the proposal idea, designed and write the proposal, supervised sample collection and the laboratory analysis, performed data entry, clearance, analysis, interpretation of the findings, drafting the manuscript and approved the final manuscript

\section{Funding}

This work was supported by Hawassa University College of Medicine and Health Science to cover transportation fees for data collectors and the cost of ELISA kits. But it had no role in the design data collection, analysis, interpretation of data and writing the manuscript. The author also declares that no other financial fund was secured from other sources for this research work.

\section{Availability of data and materials}

The datasets generated and analyzed during the current study are not publicly available because they are archived in the database of the Hawassa University research and technology transfer Vice president Database Center and only are used for scientific purposes. Datasets may be available from the corresponding authors upon request

\section{Ethics approval and consent to participate}

The research was approved by the Institutional Review Board (IRB) of Hawassa University College of medicine and health science on 14 February 2017 and approved the proposal with (Reference number: IRB -057-14- 02/ 2017). An original copy of the approval, as well as the consent form, is available upon request. Written informed consent was taken from all study participants according to national research guidelines and regulations of the Ministry of Health.

Permission was obtained from Hawassa University, College of health science comprehensive and specialized hospital and Yirgalem hospital to collect sociodemographic and risk factors and blood sample collection.

\section{Consent for publication}

Not applicable.

\section{Competing interests}

The authors declare that they have no competing interests.

Received: 8 January 2019 Accepted: 9 December 2019

Published online: 16 December 2019

\section{References}

1. Jones J, Dubey J. Foodborne toxoplasmosis. Clin Infect Dis. 2012;55(6):84551. https://doi.org/10.1093/cid/cis508 Review.

2. Klevar S. Tissue cyst forming coccidia; toxoplasma gondii and Neospora caninum as a cause of disease in farm animals. Acta Vet Scand. 2007;49(1):S1.

3. Ray CG, Ryan KJ. Sherri's medical microbiology: an introduction to infectious diseases. 6th ed.Sydney: McGraw-Hill; 2004.
4. Montoya JG, Huffman HB, Remington J. Evaluation of the immunoglobulin $\mathrm{G}$ avidity test for diagnosis of toxoplasmic lymphadenopathy. J Clin Microbiol. 2004;42(10):4627-31.

5. Negash T, Tilahun G, Medhin G. Seroprevalence of toxoplasma gondii in Nazareth town, Ethiopia. East Afr J Public Health. 2008;5(3):211-4.

6. Pappas G, Roussos N, Falagas ME. Toxoplasmosis snapshots: global status of toxoplasma gondii seroprevalence and implications for pregnancy and congenital toxoplasmosis. Int J Parasitol. 2009;39(12):1385-94.

7. Flatt A, Shetty N. Seroprevalence and risk factors for toxoplasmosis among antenatal women in London: a re-examination of risk in an ethnically diverse population. Eur J Pub Health. 2012;23(4):648-52.

8. Tegegne D, Abdurahman M, Mosissa T, Yohannes M. Anti-toxoplasma antibodies prevalence and associated risk factors among HIV patients. Asian Pac J Trop Med. 2016;9(5):460-4.

9. Mosti M, Pinto B, Giromella A, Fabiani S, Cristofani R, Panichi M, Bruschi F. A 4-year evaluation of toxoplasmosis seroprevalence in the general population and women of reproductive age in Central Italy. Epidemiol Infect. 2013;141(10):2192-5.

10. Abdel-Raouff M, Elbasheir MM. Sero-prevalence of toxoplasma gondii infection among pregnant women attending antenatal clinics in Khartoum and Omdurman maternity hospitals, Sudan. J Coastal Life Med. 2014;2(6):496-9.

11. Carral L, Kaufer F, Olejnik P, Freuler C, Durlach R. Prevention of congenital toxoplasmosis in a Buenos Aires hospital. Medicine. 2013;73(3):238-42.

12. Demographic IE. Health survey 2016: key indicators report. Addis Ababa, Ethiopia, and Rockville: CSA and ICF; 2016.

13. Zemene E, Yewhalaw D, Abera S, Belay T, Samuel A, Zeynudin A. Seroprevalence of toxoplasma gondii and associated risk factors among pregnant women in Jimma town, Southwestern Ethiopia. BMC Infect Dis. 2012;12(1):337.

14. Endris M, Belyhun Y, Moges F, Adefiris M, Tekeste Z, Mulu A, Kassu A. Seroprevalence and associated risk factors of toxoplasma gondii in pregnant women attending in Northwest Ethiopia. Iran J Parasitol. 2014;9(3):407.

15. Gelaye W, Kebede T, Hailu A. High prevalence of anti-toxoplasma antibodies and absence of toxoplasma gondii infection risk factors among pregnant women attending routine antenatal care in two hospitals of Addis Ababa, Ethiopia. Int J Infect Dis. 2015:34:41-5.

16. Gebremedhin EZ, Abebe AH, Tessema TS, Tullu KD, Medhin G, Vitale M, Di Marco V, Cox E, Dorny P. Seroepidemiology of toxoplasma gondii infection in women of child-bearing age in Central Ethiopia. BMC Infect Dis. 2013;13(1):101.

17. Yohanes T, Debalke S, Zemene E. Latent toxoplasma gondii infection and associated risk factors among HIV-infected individuals at Arba Minch hospital, South Ethiopia. AIDS Res Treat. 2014;2014

18. Abamecha $\mathrm{F}$, Awel H. Seroprevalence and risk factors of toxoplasma gondii infection in pregnant women following antenatal care at Mizan Aman general hospital, bench Maji zone (BMZ), Ethiopia. BMC Infect Dis. 2016;16(1):460.

19. Elsheikha HM, Azab MS, Abousamra NK, Rahbar MH, Elghannam DM, Raafat D. Seroprevalence of and risk factors for toxoplasma gondii antibodies among asymptomatic blood donors in Egypt. Parasitol Res. 2009:104(6):1471-6.

20. Eshete H, Tessema S, Abebe S, Abebe A. Some notes on toxoplasmosis in pregnant women in Addis Abeba. Ethiop Med J. 1994:32(2):135.

21. Lindström I, Kaddu-Mulindwa DH, Kironde F, Lindh J. Prevalence of latent and reactivated toxoplasma gondii parasites in HIV-patients from Uganda. Acta Trop. 2006;100(3):218-22.

22. Shimelis T, Tebeje M, Tadesse E, Tegbaru B, Terefe A. Sero-prevalence of latent toxoplasma gondii infection among HIV-infected and HIV-uninfected people in Addis Ababa, Ethiopia: a comparative cross-sectional study. BMC Res Notes. 2009;2(1):213.

23. Torgerson PR, Macpherson CN. The socioeconomic burden of parasitic zoonoses: global trends. Vet Parasitol. 2011;182(1):79-95.

24. Mohammad HA, Amin T, Balaha M, Moghannum MA. Toxoplasmosis among the pregnant women attending a Saudi maternity hospital: seroprevalence and possible risk factors. Ann Trop Med Parasitol. 2010;104(6):493-504.

25. Wallon M, Peyron F, Cornu C, Vinault S, Abrahamowicz M, Kopp CB, Banquet C. Congenital toxoplasma infection: monthly prenatal screening decreases transmission rate and improves clinical outcome at age 3 years. Clin Infect Dis. 2013;56(9):1223-31. 
26. Dawit G, Shishay K. Epidemiology, public health impact and control methods of the most neglected parasite diseases in Ethiopia: a review. World J Med Sci. 2014;10:94-102.

27. Njunda AL, Assob JC, Nsagha DS, Kamga HL, Nde PF, Yugah VC. Seroprevalence of Toxoplasma gondii infection among pregnant women in Cameroon. J Public Health Afr. 2011;2(2):98-101.

28. Hatam G, Shamseddin A, Nikouee F. Seroprevalence of toxoplasmosis in high school girls in Fasa district, Iran. Iran J Immunol. 2005;2(3):177-81.

29. Alvarado-Esquivel C, del Carmen T-SM, Hernández-Tinoco J, Muñoz-Terrones MDE, Gallegos-González RO, Sánchez-Anguiano LF, Reyes-Robles ME, Jaramillo-Juárez F, Liesenfeld O, Estrada-Martínez S. Seroepidemiology of toxoplasma gondii in pregnant women in Aguascalientes City, Mexico: a cross-sectional study. BMJ Open. 2016;6(7):e012409.

30. Murebwayire E, Njanaake K, Ngabonziza JCS, Jaoko W, Njunwa KJ. Seroprevalence and risk factors of Toxoplasma gondii infection among pregnant women attending antenatal care in Kigali, Rwanda. Tanzan J Health Res. 2017;19(1)

31. Weese S. Pets and immune-compromised people. In: Worms \& Germs Blog: Ontario Veterinary College's Centre for Public Health and Zoonoses; 2008.

32. Ertug S, Okyay P, Turkmen M, Yuksel H. Seroprevalence and risk factors for toxoplasma infection among pregnant women in Aydin province, Turkey. BMC Public Health. 2005;5(1):66

33. Majid A, Khan S, Jan AH, Taib M, Adnan M, Ali I, Khan SN. Chronic toxoplasmosis and possible risk factors associated with pregnant women in Khyber Pakhtunkhwa. Biotechnol Biotechnol Equip. 2016;30(4):733-6.

34. Mwambe B, Mshana SE, Kidenya BR, Massinde AN, Mazigo HD, Michael D, Majinge C, Groß U. Seroprevalence and factors associated with toxoplasma gondii infection among pregnant women attending antenatal care in Mwanza, Tanzania. Parasit Vectors. 2013;6(1):222.

35. Kamal AM, Ahmed AK, Abdellatif MZ, Tawfik M, Hassan EE. Seropositivity of toxoplasmosis in pregnant women by ELISA at Minia University hospital, Egypt. Korean J Parasitol. 2015:53(5):605.

36. Wam EC, Sama LF, Ali IM, Ebile WA, Aghangu LA, Tume CB. Seroprevalence of toxoplasma gondii $\lg G$ and $\lg M$ antibodies and associated risk factors in women of child-bearing age in Njinikom, NW Cameroon. BMC Res Notes. 2016;9(1):406.

37. Mandour A, Mounib M, Eldeek H, Ahmad A, Abdel-Kader A. Prevalence of congenital toxoplasmosis in pregnant women with complicated pregnancy outcomes in Assiut governorate, Egypt. J Adv Parasitol. 2017:4(1):1-8.

38. Deji-Agboola A, Busari O, Osinupebi O, Amoo A. Seroprevalence of toxoplasma gondii antibodies among pregnant women attending antenatal clinic of Federal Medical Center, Lagos, Nigeria. Int J Biol Med Res. 2011;2(4):1135-9.

39. Awoke K, Nibret E, Munshea A. Seroprevalence and associated risk factors of toxoplasma gondii infection among pregnant women attending antenatal care at Felege Hiwot referral hospital, Northwest Ethiopia. Asian Pac J Trop Med. 2015;8(7):549-54

40. Ramsewak S, Gooding R, Ganta K, Seepersadsingh N, Adesiyun AA. Seroprevalence and risk factors of toxoplasma gondii infection among pregnant women in Trinidad and Tobago. Rev Panam Salud Publica. 2008;23:164-70

41. Alghamdi J, Elamin MH, Alhabib S. Prevalence and genotyping of toxoplasma gondii among Saudi pregnant women in Saudi Arabia. Saudi Pharm J. 2016;24(6):645-51.

42. Fan C-K, Hung C-C, Su K-E, Chiou H-Y, Gil V, Ferreira MCR, Tseng L-F. Seroprevalence of toxoplasma gondii infection among inhabitants in the Democratic Republic of Sao Tome and Principe. Trans R Soc Trop Med Hyg. 2007:101(11):1157-8

43. Elnahas A, Gerais AS, Elbashir MI, Eldien ES, Adam I. Toxoplasmosis in pregnant Sudanese women. Saudi Med J. 2003;24(8):868-70.

44. Evengård $B$, Petersson $K$, Engman M, Wiklund S, Ivarsson S, Teär-Fahnehjelm K, Forsgren M, Gilbert R, Malm G. Low incidence of toxoplasma infection during pregnancy and in newborns in Sweden. Epidemiol Infect. 2001;127(1):121-7.

45. Mosti M, Pinto B, Giromella A, Fabiani S, Cristofani R, Panichi M, Bruschi F. A 4-year evaluation of toxoplasmosis seroprevalence in the general population and women of reproductive age in Central Italy; 2012

46. Song K-J, Shin J-C, Shin H-J, Nam H-W. Seroprevalence of toxoplasmosis in Korean pregnant women. Korean J Parasitol. 2005:43(2):69.

47. Agmas B, Tesfaye R, Koye DN. Seroprevalence of toxoplasma gondii infection and associated risk factors among pregnant women in Debre Tabor, Northwest Ethiopia. BMC Res Notes. 2015;8(1):107.
48. Ayi I, Edu S, Apea-Kubi K, Boamah D, Bosompem K, Edoh D. Seroepidemiology of toxoplasmosis amongst pregnant women in the Greater Accra region of Ghana. Ghana Med J. 2009;43(3).

49. Khalil K, Ahmed A, Elrayah I. Sero-prevalence of toxoplasma gondii infection in humans in Khartoum state, Sudan. Int J Trop Med. 2012;7:43-50.

50. Alvarado-Esquivel C, Sifuentes-Álvarez A, Narro-Duarte SG, Estrada-Martínez S, Díaz-García JH, Liesenfeld O, Martínez-García SA, Canales-Molina A. Seroepidemiology of toxoplasma gondii infection in pregnant women in a public hospital in northern Mexico. BMC Infect Dis. 2006;6(1):113.

51. Tavares MS, Araújo RM, Abud ACF, Alves JAB, Nunes MS, Inagaki ADM. Toxoplasmosis in pregnant women: prevalence, risk factors and prevention actions; 2012

52. Bamba S, Cissé M, Sangaré I, Zida A, Ouattara S, Guiguemdé RT. Seroprevalence and risk factors of toxoplasma gondii infection in pregnant women from Bobo Dioulasso, Burkina Faso. BMC Infect Dis. 2017:17(1):482.

\section{Publisher's Note}

Springer Nature remains neutral with regard to jurisdictional claims in published maps and institutional affiliations.
Ready to submit your research? Choose BMC and benefit from:

- fast, convenient online submission

- thorough peer review by experienced researchers in your field

- rapid publication on acceptance

- support for research data, including large and complex data types

- gold Open Access which fosters wider collaboration and increased citations

- maximum visibility for your research: over $100 \mathrm{M}$ website views per year

At $\mathrm{BMC}$, research is always in progress.

Learn more biomedcentral.com/submissions 